\title{
Determination of differences in temperature regimes on healthy and bark-beetle colonised spruce trees using a handheld thermal camera
}

\author{
Andrej Majdák (1), \\ Rastislav Jakuš (1-2), \\ Miroslav Blaženec ${ }^{(1)}$
}

\begin{abstract}
In this study, we compared the daily temperature regimes of healthy uninfected trees in the interior of a forest stand and at the fresh forest edge with infested trees at the forest edge in an area affected by a bark beetle outbreak. We estimated the potential of a handheld thermal camera for early identification of bark-beetle infested trees. We show that infested trees have significantly higher trunk temperatures than uninfested trees, which is more visible on the shine side of the trunk, and we report the differences in temperature between the shine and shadow sides. The differences are more noticeable on a warm, bright, and sunny day than on cold and cloudy day. The different intensity of solar radiation does not affect the distinction between infested and uninfested trees. The handheld thermal camera shows potential for identifying bark-beetle infested trees by scanning tree trunks on bright sunny days.
\end{abstract}

Keywords: Bark-beetle Infested Trees, Handheld Thermal Camera, Incoming Solar Radiation, Norway Spruce, Solar Radiation Modelling, Temperature Differences

\begin{abstract}
Introduction
Stands of mature Norway spruce (Picea abies [L.] Karst.) are often attacked by European spruce bark beetle (Ips typographus L.). In response to climatic changes and especially to increases in maximal temperatures, the extent of damage caused by these beetles is significantly increasing (Mezei et al. 2017). In mountainous conditions, l. typographus prefers to attack trees on fresh forest edges or in small openings caused by wind damage, salvage cutting, or previous bark beetle infestation (Jakuš et al. 2011, Kautz et al. 2013). Undisturbed spruce stands are usually well protected against direct insolation by individual and/ or collective shading (Jakuš et al. 2011). Natural disturbances, such as windthrows or bark beetle infestation gaps, create new forest edges within a stand, which show a sharp microclimatic gradient. The altered microclimate is characterised by increased solar radiation, wind exposure, higher temperatures, and lower humidity (Kautz et al.
\end{abstract}

2013). Higher air temperatures at cleared edges, associated with increased solar radiation, predispose such edge trees to infestation by providing favourable flight conditions for bark beetles and by reducing host resistance mechanisms due to drought or thermal stress on dispersing beetles (Kautz et al. 2013). Higher temperatures on sunexposed bark can increase the emission of primary bark beetle attractants (Baier \& Bader 1997, Hietz et al. 2005, Marešová et al. 2020). During host selection, bark beetles prefer warmer trees (Kautz et al. 2013). Another factor is connected with sun-related effects. A clear cut of a recent infestation patch will lead to sudden sun exposure to large parts of the stems of the edge trees, which were previously located within a closed stand and are thus characterised by relatively short crowns. Sun exposure without any prior adaptation to the altered microclimate, particularly on southfacing cleared edges, may result in heatdamaged phloem and increased transpira-
(1) Institute of Forest Ecology, Slovak Academy of Sciences, Ludovíta Štúra 2, $96053 \mathrm{Zv}$ olen (Slovak Republic); (2) Faculty of Forestry and Wood Sciences, Czech University of Life Sciences, Kamýcká 1176, 16521 Praha 6 - Suchdol (Czech Republic)

@ Andrej Majdák (andrej.majdak@gmail.com)

Received: May 21, 2020 - Accepted: Feb 23, 2021

Citation: Majdák A, Jakuš R, Blaženec M (2021). Determination of differences in temperature regimes on healthy and bark-beetle colonised spruce trees using a handheld thermal camera. iForest 14: 203-211. - doi: 10.3832/ifor3531-014 [online 2021-05-02]

Communicated by: Carlotta Ferrara tion rates, and may eventually lead to trees being subjected to drought stress (Kautz et al. 2013, Marešová et al. 2020).

To some extent, trees can influence their thermal environment and thereby avoid excessive heat or enhanced temperatures during otherwise hot conditions (Leuzinger \& Körner 2007). According to Helliker \& Richter (2008), the morphological and physiological characteristics of a tree canopy work to maintain leaf temperatures near the optimal value for photosynthesis (about $21{ }^{\circ} \mathrm{C}$ ), irrespective of tree species, latitude, or average growing season temperatures. In warmer climates, leaf temperatures are lowered by evaporative cooling and mechanisms that reduce the absorbance of solar radiation, such as decreased leaf angles. However, the architecture of an individual tree changes only marginally during a few weeks of drought. On bright, warm days, the difference between canopy foliage and air temperature is mainly the result of transpiration. Longer drought periods increase canopy foliage temperatures (Scherrer et al. 2011). Stress induced by an invasion of insects or the onset of disease leads to, among other symptoms, stomatal closure and, consequently, to increased leaf and canopy temperatures (Smigaj et al. 2015). This temperature rise can often be detected at the leaf level at an early stage of infection by thermal imaging. However, research on the use of thermal remote sensing approaches for tree health monitoring has been limited (Smigaj et al. 2015). The development of handheld thermal cameras has allowed thermal imaging to be extended to the diagnosis of the physiological status of both woodland 
trees and individual urban trees (Jones 2004).

The cooling effect of sap flow can help keep tree bole temperatures lower. According to Hietz et al. (2005), during daylight hours, the bark is warmed by the surrounding air and direct radiation. The high water content of sapwood dampens the daily temperature fluctuations in the bole; transpiration water passing through the sapwood, which enters the stem base at the temperature of the soil, will remove heat and cool the cambium and the inner parts of the secondary phloem.

During attack and colonization, bark beetles disrupt two basic life-sustaining transport processes of the trees they infest. In the early phase of overcoming tree host defences, adult beetles enter a suitable host by boring through the outer bark and into the phloem, and consume phloem tissue to build egg galleries; developing larvae consume phloem for food until maturity. Together, phloem feeding by adults and larvae contributes to some amount of phloem girdling, disrupting the transport of photosynthate from the canopy to other tissues within the tree (Paine et al. 1997, Wullschleger et al. 2004, Hubbard et al. 2013). Later, phytopathogenic fungal spores introduced by bark beetles germinate, and the spreading fungal hyphae penetrate the water-conducting xylem tissue in the sapwood and block water transport from the soil to the canopy (Wullschleger et al. 2004, Hubbard et al. 2013). Transpiration can begin to decline within the first weeks of beetle infestation. After several weeks, pre-dawn water potential drops significantly as water transport to the canopy significantly declines. In the early stages, there may be no visible signs of needle discoloration (Kirisits \& Offenthaler 2002, Hubbard et al. 2013). The subsequent death of the tree (staining or occlusion of sapwood, fading of foliage) may occur long after the critical interactions between the tree and beetle/fungus complex (Paine et al. 1997). Wullschleger et al. (2004) showed that when xylem function begins to fail, the progeny of attacking beetles would have already departed the tree, and the phloem and cambium would have been so thoroughly girdled that mortality was assured long before any effects on sap velocity were observed.

Early detection of infested trees is crucial for the effective management of bark beetle outbreaks (Latifi et al. 2014). Infested trees begin to undergo changes in their spectral characteristics (Abdullah et al. 2018), which can be effectively detected using remote sensing (RS) techniques, e.g., unmanned aerial vehicles (UAV), satellites, and thermal imaging (Lausch et al. 2016, Lausch et al. 2017). Thermal imaging, based on terrestrial sensors or handheld thermal cameras, has been used for a wide range of conditions and with diverse plant species. The technique can be applied at different scales: from single seedlings/leaves (Buitrago et al. 2016) to whole trees or field crops and regions (Costa et al. 2013). It shows significant potential for studying plant-environment interactions and specific phenomena, such as stomatal closure, stress tolerance, and the effects of different management strategies on crop water status and tree health (Jones 2004, Reinert et al. 2012, Costa et al. 2013). However, using a handheld thermal camera for identifying barkbeetle infested trees based on trunk temperature sensing has not yet been described.

In our study, we aimed to compare daily temperature regimes of healthy uninfested trees in the stand interior and at a fresh forest edge and infested trees at the forest edge in areas affected by a bark beetle outbreak. We also estimated the potential of a handheld thermal camera for early identification of bark-beetle infested trees. We were specifically interested in the following: (1) What is the proper height for sensing trees for mutual comparison (base, 1.3 $\mathrm{m}, 4 \mathrm{~m}$, or crown) to find the differences between uninfested and bark-beetle infested trees? (2) Is it possible to distinguish between uninfested and bark-beetle infested trees based on temperature? (3) How much is the temperature difference affected by direct solar radiation and does that prevent the identification of infested trees? (4) Can phloem temperature be derived from thermal imaging by handheld thermal cameras?

Tab. 1 - Mean values ( \pm standard error, SE) of selected tree characteristics between the plots and results of ANOVA $\left(\mathrm{F}_{[1,2]}, \alpha=0.05\right)$. (*): diameter at breast height; $(* *)$ : trees creating the surrounding forest stand and assessed for the purpose of modelling the light distribution in the MIXLIGHT model.

\begin{tabular}{lllll}
\hline Stats & Plot & $\begin{array}{l}\mathrm{DBH}^{*} \\
(\mathbf{c m})\end{array}$ & $\begin{array}{l}\text { Height } \\
(\mathbf{m})\end{array}$ & $\begin{array}{l}\text { Crown length } \\
(\mathbf{m})\end{array}$ \\
\hline $\begin{array}{l}\text { Mean tree } \\
\text { characteristics } \\
( \pm \mathrm{SE})\end{array}$ & $\mathrm{A}$ & $38.6 \pm 1.80$ & $37.2 \pm 1.11$ & $18.2 \pm 0.92$ \\
& $\mathrm{~B}$ & $34.0 \pm 1.70$ & $37.0 \pm 1.08$ & $16.7 \pm 0.44$ \\
& $\mathrm{C}$ & $36.0 \pm 2.26$ & $38.6 \pm 0.93$ & $17.6 \pm 0.85$ \\
& other** & $36.8 \pm 0.49$ & $38.7 \pm 0.26$ & $17.5 \pm 0.27$ \\
ANOVA results & $\mathrm{F}_{[3,103]}$ & 0.90 & 1.16 & 0.30 \\
\cline { 2 - 5 } & $\mathrm{p}$-value & 0.45 & 0.33 & 0.82 \\
\hline
\end{tabular}

\section{Materials and methods}

\section{Research site}

The study plots were set up in a 90-yearold Norway spruce stand (Picea abies [L.] Karst.) on a moderately southwest-exposed slope at 650-730 $\mathrm{m}$ a.s.l. in the Western Carpathians, Central Slovakia, Michalová forest district $\left(48^{\circ} 45^{\prime} 55.85^{\prime \prime} \mathrm{N}, 19^{\circ} 47^{\prime}\right.$ 31.18" S; WGS84). The mean annual climate indicators of the research site were as follows: air temperature, $4-6{ }^{\circ} \mathrm{C}$; precipitation, 900-1000 mm; sum of global radiation, 1100-1150 kWh m² (Lapin et al. 2002). The soil is classified as Dystric Cambisols and Cambic Umbrisols, associated with Leptosols, from weathering products of acid to neutral rocks (Lapin et al. 2002) according to the World Reference Base (WRB) classification system (IUSS Working Group 2014).

\section{Research design and measurements}

For our observations, three groups of trees were selected. Two groups contained healthy trees, not infested by bark beetles, and one contained infested trees. There were five trees in each group. The first group of healthy trees was selected in the forest interior (plot A, Interior_Uninfested) and the second at the newly created forest edge (plot B, Edge_Uninfested). The group of five infested trees (plot C, Edge Infested) was selected at another newly created forest edge close to the two groups of healthy trees, about $150 \mathrm{~m}$ apart. The trees were selected from the dominant and codominant trees in the forest stand, and the mean values of selected tree characteristics of the observed tree groups are listed in Tab. 1. The measurements were recorded in two days. The first day (20 August 2012) was sunny with high temperatures, with a maximum air temperature in the open area close to the forest edge reaching $31.7^{\circ} \mathrm{C}$ and the sum of global radiation totalling $5588 \mathrm{Wm}^{-2}$ (Fig. 1a). The second day (10 October 2012) was cloudy and cold, with a maximum air temperature of $9.2^{\circ} \mathrm{C}$ and sum of global radiation of 1452 $\mathrm{Wm}^{-2}$ (Fig. 1b). Twenty days before the first day of measurement, there was almost no precipitation; the total for this period was $2.6 \mathrm{~mm}$. This means that the conditions were not only hot but also relatively dry before the first day of measurement. The weather characteristics in the 20 days before each measurement day are presented in more detail in Tab. 2 .

Images of stem and crown temperatures were captured using a $\mathrm{WH}-8$ thermal camera (Wuhan Guide Infrared Co., Ltd., China), with a focal plane array (FPA) and uncooled microbolometer with a resolution of $384 \times 288$ pixels. The spectral range was $8-14 \mu \mathrm{m}$ and the sensitivity was $\leq 0.08$ ${ }^{\circ} \mathrm{C}$ at $30^{\circ} \mathrm{C}$. The emissivity of imaging was set to 0.96. For trees in plot A (Interior_Uninfested, two trees) and plot B (Edge Uninfested, three trees), the temperature of phloem close to the place sensed by the in- 
Fig. 1 - Daily course of global radiation and air temperature in an open area close to plots and in the forest interior during measurement days: (a) warm and sunny day and (b) cold and cloudy day.

Air temperature in the open area is represented by a solid black line and by a solid grey line in the forest interior. Global radiation is represented by a dotted black line.
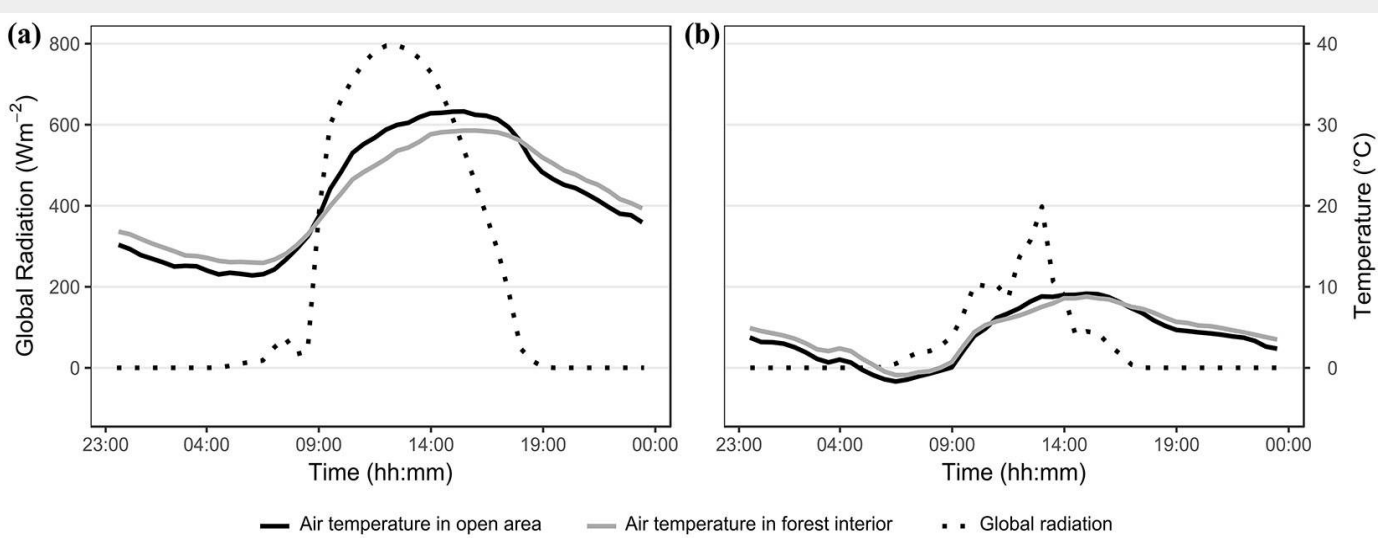

frared camera was recorded continuously using thermal sensors inserted into the phloem (EMS, Brno, Czech Republic), connected to a datalogger and stored in 15minute intervals. The obtained infrared pictures were processed with IR Analyser software (Wuhan Guide Infrared Co., Ltd., China). To eliminate local inaccuracies of stem temperatures caused by sunlight penetrating through the canopy, we selected an area of about $20 \times 20 \mathrm{~cm}$ of the observed stem, from which the average temperature was obtained (Fig. 2).

Thermal pictures of each tree trunk were captured at three heights: at the base and at 1.3 and $4 \mathrm{~m}$ on both the shine and shadow sides; the temperature of the tree crown was taken from the ground. The shine side was the part of the tree trunk facing direct sun every time a thermal image was captured, and the shadow side was on the opposite side. The images were captured in approximately one hour intervals from morning hours after sunrise to evening hours when the sun was no longer
Tab. 2 - Course of weather characteristics in the 20 days before each day of measurement (20 August and 10 October 2012).

\begin{tabular}{|c|c|c|c|}
\hline Parameter & Stats & 31 July - 19 Aug. 2012 & 20 Sept. - 9 Oct. 2012 \\
\hline \multirow{3}{*}{$\begin{array}{l}\text { Air temperature } \\
\left({ }^{\circ} \mathrm{C}\right)\end{array}$} & Avg & 17.6 & 11.8 \\
\hline & Min & 4.5 & -0.5 \\
\hline & $\operatorname{Max}$ & 34.2 & 24.3 \\
\hline \multirow{3}{*}{$\begin{array}{l}\text { Relative air humidity } \\
(\%)\end{array}$} & Avg & 72 & 80 \\
\hline & Min & 32 & 37 \\
\hline & $\operatorname{Max}$ & 100 & 100 \\
\hline Precipitation (mm) & Sum & 2.6 & 30.6 \\
\hline \multirow{3}{*}{ 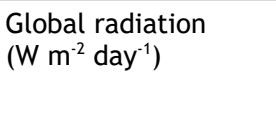 } & Avg & 4722 & 2847 \\
\hline & Min & 1047 & 786 \\
\hline & $\operatorname{Max}$ & 6532 & 5299 \\
\hline
\end{tabular}

shining on the plots. The last interval lasted surements on all plots on the second day two hours. We captured nine measure- (10 October 2012). In the open area, air ments on plots A (Interior_Uninfested) and temperature and global radiation were $B$ (Edge_Uninfested) and eight measure- measured at half-hour intervals using a ments on plot C (Edge_Infested) on the Minikin RT ${ }^{\oplus}$ (EMS, Brno, Czech Republic). first day (20 August 2012), and nine mea- Air temperature was simultaneously mea-
Fig. 2 - Thermal image and RGB photo from $1.3 \mathrm{~m}$ height captured using a thermal camera: (a) shine side of a tree; and (b) shadow side of a tree. On the thermal image, an area of approximately $20 \times$ $20 \mathrm{~cm}$ in the middle of the observed stem was selected for obtaining the average temperature. On the right or left side of the stem is an auxiliary scale visible for easier identification of the required height on the thermal image.

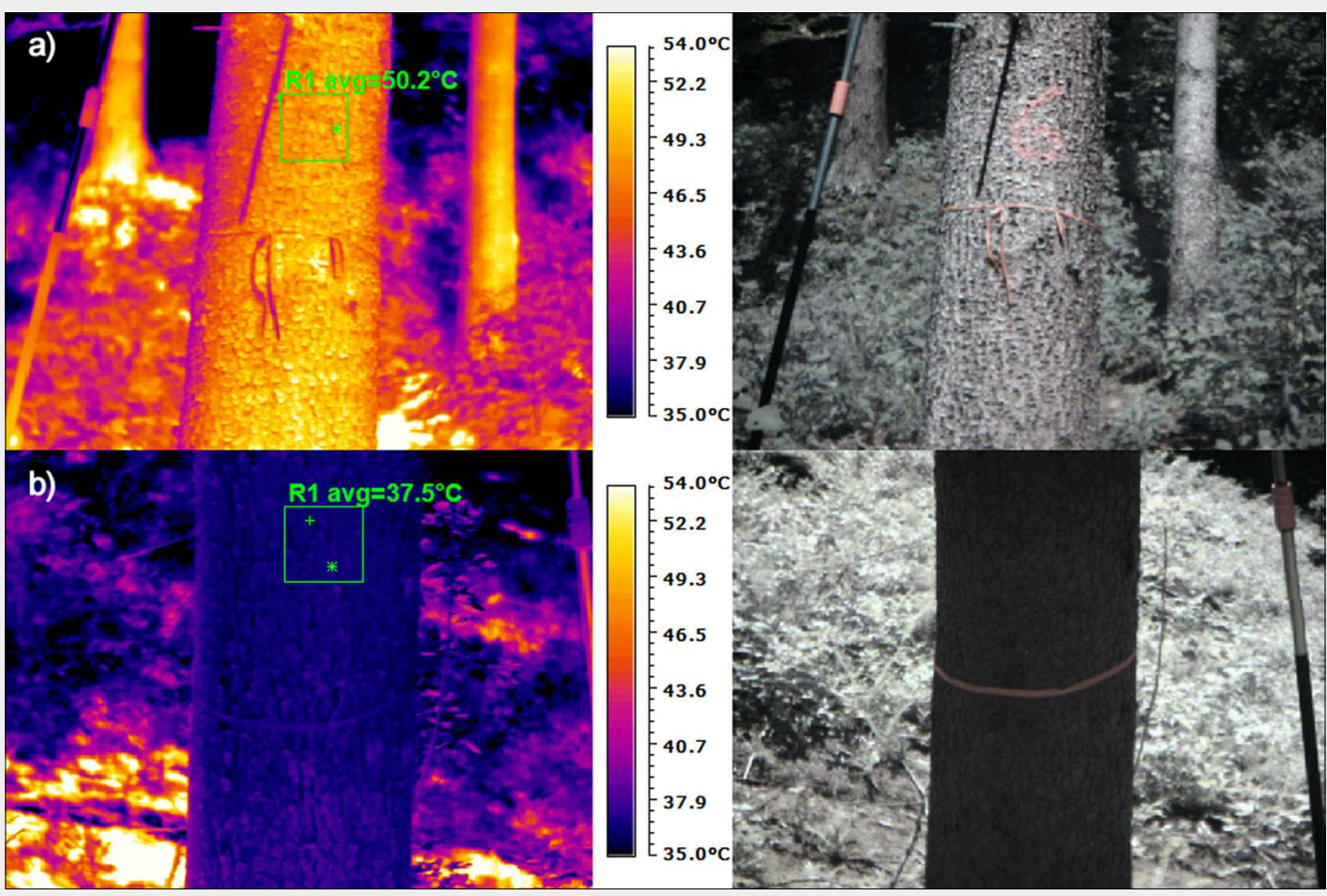




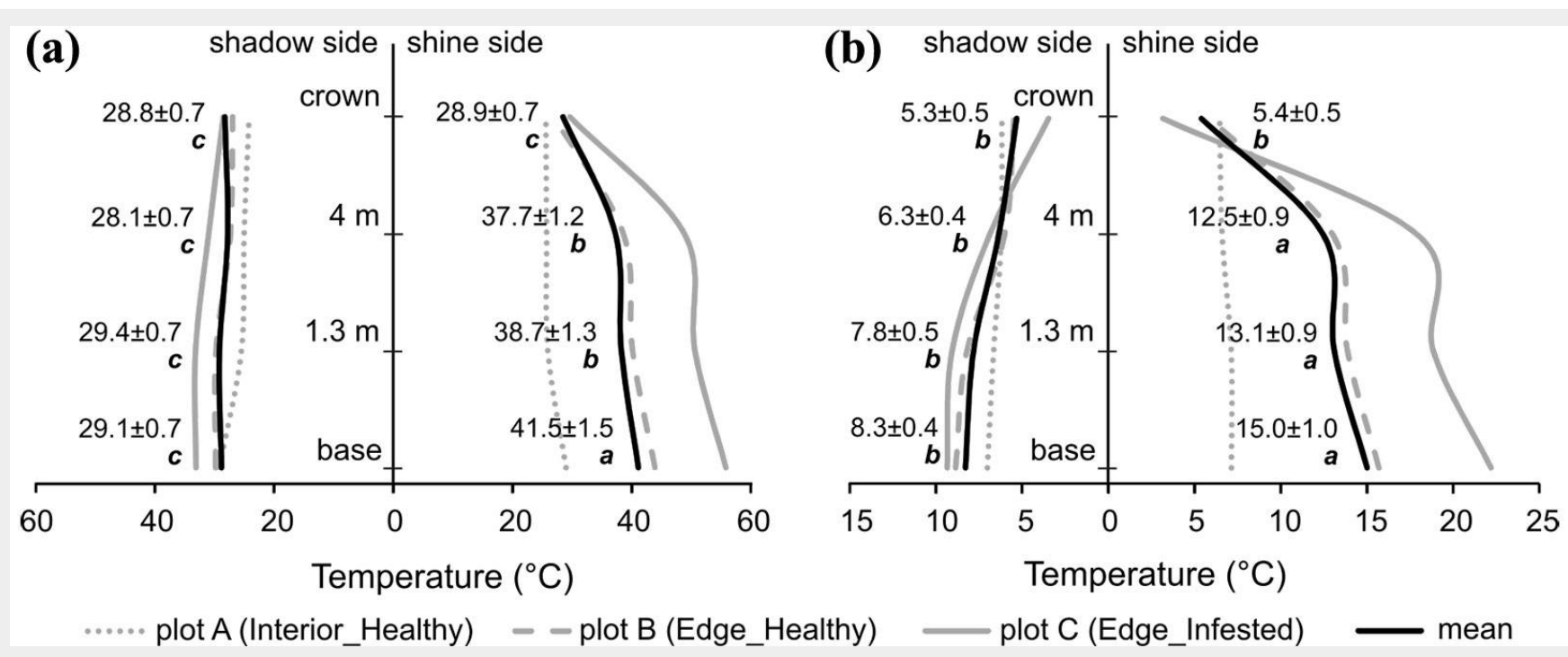

Fig. 3 - Vertical mean temperature profile from measurements on both shine and shaded sides of trees on (a) warm and sunny days and (b) cold and cloudy days. Mean temperatures from uninfested trees in the forest interior (plot A) are represented by dotted grey lines, from uninfested trees on the forest edge (plot B) by dashed grey lines, and from bark-beetle-infested trees on the forest edge (plot C) by solid grey lines. Solid black lines represent total mean temperatures from all plots. Statistically different groups of total mean temperatures between the heights on both shine and shaded sides of trees within each measuring day separately were determined according to Tukey's test $(\alpha=0.05)$ and are highlighted by different lowercase letters.

sured in the forest interior using a Minikin $\mathrm{TH}^{\circledast}$ (EMS, Brno, Czech Republic).

\section{Solar radiation modelling}

The amount of solar radiation at each measurement point (height on the stem) was recalculated using the MIXLIGHT model (Stadt \& Lieffers 2000), which is used to calculate solar radiation passing through tree crowns. The input to the model was data obtained with an Ilris $\mathrm{HD}^{\circledR}$ terrestrial laser scanner (Teledyne Optech, Canada). The scanning method was chosen to produce the best possible representation of the forest stand structure. The focus was not only on selected trees in individual plots, but on all trees at a distance of at least 3 times the average height of trees from experimental areas. The point cloud was processed in the Polyworks ${ }^{\mathrm{TM}} \mathrm{v} .12$ software environment (InnovMetric Software, Canada), where the scan was then georeferenced into the WGS84 geodetic system. Geometric characteristics of the trees were obtained manually from the created point cloud. The parameters that were detected were tree height, diameter at breast height (DBH), trunk coordinates, crown deployment height, crown parameters, and tree social status. After entering the tree characteristics and other characteristics, such as slope, orientation, geographic position of the area, and time (or time interval), the model quantifies the percentage of solar radiation passing through the forest stand. We used mean values from 10 minute intervals of solar radiation at the time of thermographic camera measurement. Using real solar radiation data from the weather station converted with MIXLIGHT data, we were able to calculate the real amount of solar radiation. Using a Python script, we exported individual solar radiation values at the selected height and for a particular measurement time for each tree measured by the thermographic camera.

\section{Statistics}

The data were tested by Levene's homogeneity test and the Shapiro-Wilk normality test. Given the test results, the data met the assumptions for parametric statistical methods and were statistically evaluated in R.

(1) To determine the appropriate height for thermal camera measurements, we used repeated-measure ANOVA $(a=0.05)$ for testing the temperatures at each tree height: at the base, at 1.3 and $4 \mathrm{~m}$, and at the crown, separately for the two measurement days. The relevance of the tree to the individual plot (plot $A$, Interior Uninfested; plot B, Edge_Uninfested; and plot $C$, Edge Infested) and the sensing time was not considered. Tukey's test was used to determine statistically different groups.

(2) To identify the temperature differences in $1.3 \mathrm{~m}$ height between trees on each of the three plots based on individual time of measurement and sunny and shady sides, we used ANOVA ( $\alpha=0.05)$ followed by Tukey's test.

(3) To determine the role of incoming solar radiation on the temperature of the trees in each individual plot, we used outputs from the MIXLIGHT model containing information on the recalculated global radiation for individual trees and the individual measuring times as covariates in the ANCOVA test $(\alpha=0.05)$.

(4) To determine the dependence of tree surface temperature and phloem temperature, we used linear correlation analysis. Trees from plot A (Interior_Uninfested) and plot B (Edge_Uninfested), where the phloem temperature was measured, were used in the analysis.

\section{Results}

\section{Vertical temperature profile and optimal height for thermal measurement}

The total mean temperature of the stem base on a warm and sunny day on the shine side in all plots was the highest (Fig. $3 a)$ and significantly different $(F=141.9$, df $=7, p<0.001$ ) from temperatures at other heights. With increasing measurement height, temperatures decreased, whereas at heights of 1.3 and $4 \mathrm{~m}$ did not show statistically significant differences among groups but differed from crown temperature. Temperatures on the shady side were balanced along the full height profile; together with the crown temperature on shine side, they did not show statistically significant differences among groups. On the cold and cloudy day (Fig. 3b), the mean temperatures also decreased with measurement height on both sides of the trees. The highest mean temperature was observed at the stem base from the shine side and did not differ significantly from temperatures at heights of 1.3 and $4 \mathrm{~m}$, but differed from crown temperature $(\mathrm{F}=$ 28.51, df $=7, p<0.001)$. The mean stem temperatures on the shady side together with crown temperatures on both sides did not show statistically significant differences among groups.

\section{Differences between healthy and bark- beetle infested trees}

The temperature course on the warm and sunny day (Fig. 4a) shows that bark-beetle 
Fig. 4 - Mean temperature \pm standard error (SE) at $1.3 \mathrm{~m}$ above the ground from the shine and shaded sides of trees and temperature difference \pm SE between both sides separately for both days of measurements:

(a) warm and sunny; (b) cold and cloudy. Statistical differences in temperatures between plots according to Tukey's test ( $\alpha=$ 0.05) at particular measurement times are separately highlighted by different lowercase letters at the top of subgraphs. The $X$ axis is divided for each plot $(A, B, C)$ within

each measurement, indicated by corresponding measurement times. Uninfested trees in the forest interior (plot A) are represented by solid black lines, uninfested trees on the forest edge (plot B) by solid grey lines, and bark-beetle infested trees on the forest edge (plot C) by dotted black lines.
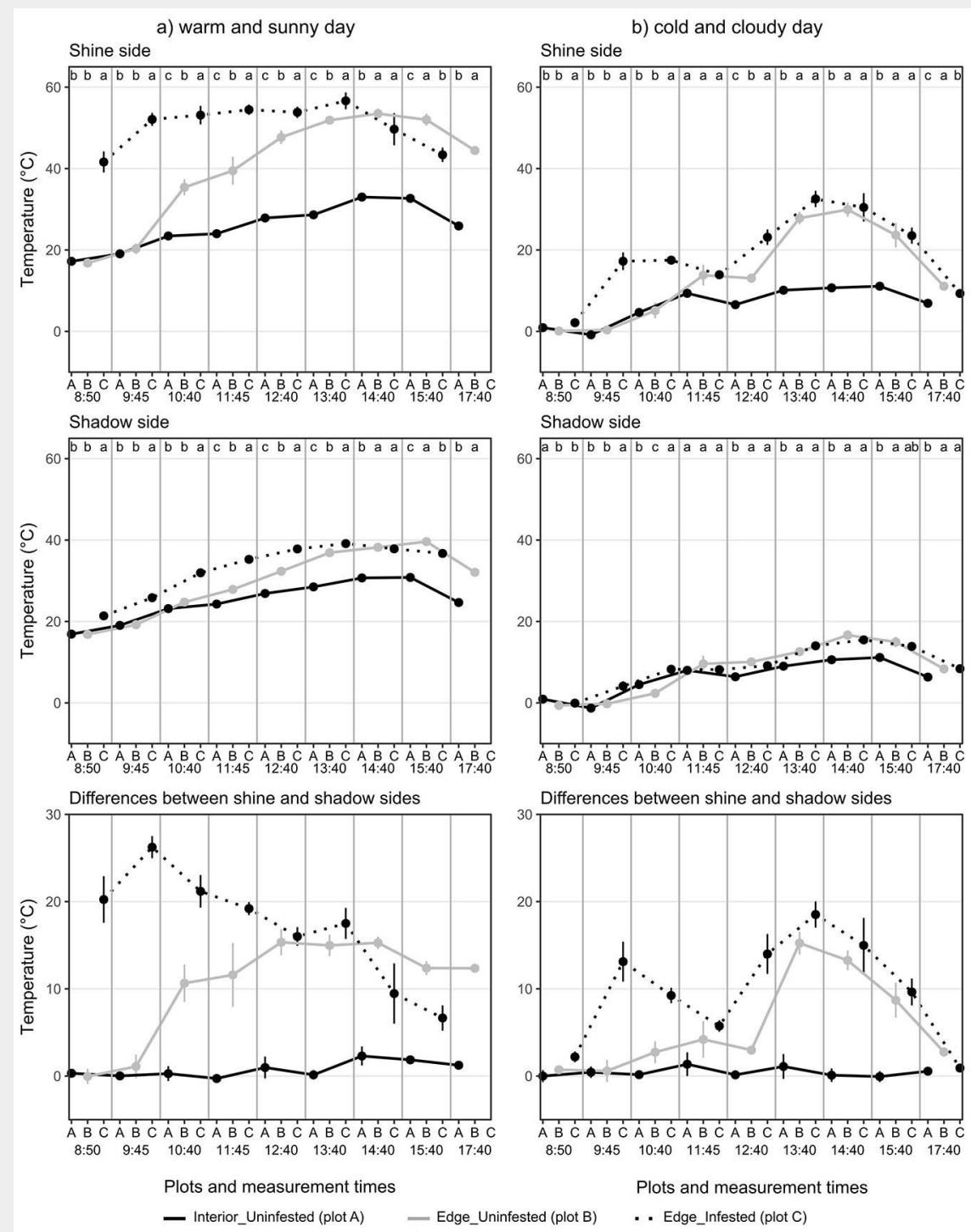

infested trees (plot C) had statistically significantly higher temperatures on the shine side since the first measurement than the uninfested trees on the forest edge (plot B) and in the forest interior (plot A). The temperature remained above $50{ }^{\circ} \mathrm{C}$ for most of the day, with first and last measurements being above $40{ }^{\circ} \mathrm{C}$, which differed from the uninfested trees in the forest interior, whose temperatures did not exceed $33^{\circ} \mathrm{C}$. The temperatures from the first six measurements were significantly higher compared to those of uninfested trees on both the shine and shaded sides. The temperatures of uninfested trees, both edge and interior, were similar for the first two measurements, with minimal differences between shine and shaded sides. The temperatures of uninfested trees on the forest edge and the interior began to differ from the third measurement on the sunny side and the fourth on the shadow side.

The temperature course on the cold and cloudy day in Fig. 4 b shows that bark-beetle infested trees (plot C) had statistically significant higher temperatures on the shine side during the first three measure- ments than the uninfested trees on the forest edge (plot B). The temperatures of uninfested trees from the shine side, both

edge (plot B) and interior (plot A) trees, remained similar for the first four measurements. They began to differ significantly
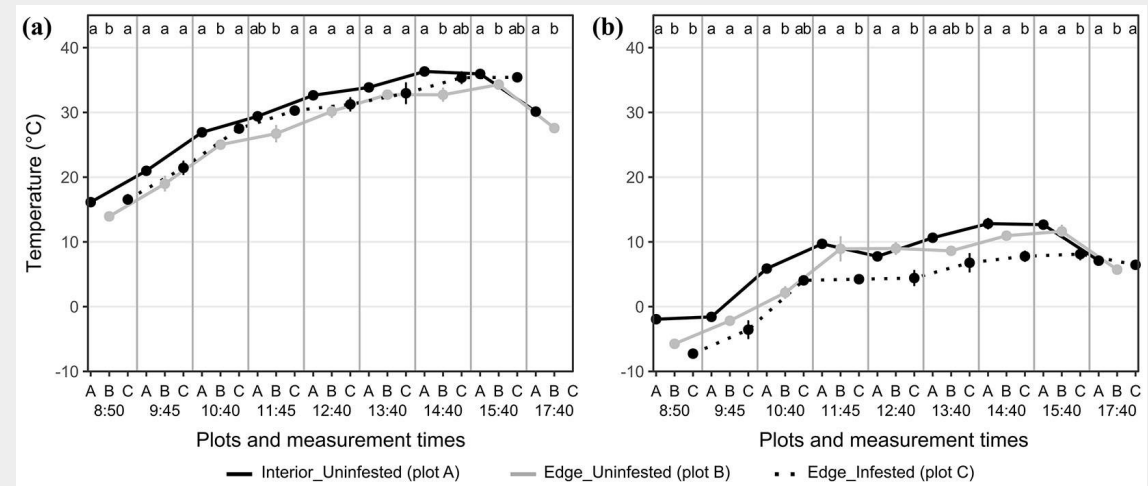

Fig. 5 - Mean crown temperature \pm SE from the shine side of trees for both measure ment days: (a) warm and sunny; (b) cold and cloudy. Statistical differences in temperature between plots according to Tukey's test $(\alpha=0.05)$ at particular measurement times are separately highlighted by different lowercase letters at the top of subgraphs. The $X$-axis is divided for each plot $(A, B, C)$ within each measurement, indicated by corresponding measurement times. Uninfested trees in the forest interior (plot A) are represented by solid black lines, uninfested trees on the forest edge (plot $\mathrm{B})$ by solid grey lines, and bark-beetle-infested trees on the forest edge (plot C) by dotted black lines. 
Tab. 3 - Results of ANCOVA comparison (F, df, p) at $\alpha=0.05$ between plots for shine and shadow sides of trees and different measurement days.

\begin{tabular}{|c|c|c|c|c|c|}
\hline \multirow{2}{*}{ Day } & \multirow{2}{*}{ Side } & \multirow{2}{*}{ Plot comparisons } & \multicolumn{3}{|c|}{ ANCOVA results } \\
\hline & & & df & $\mathbf{F}$ & $\mathrm{p}$-value \\
\hline \multirow{6}{*}{ 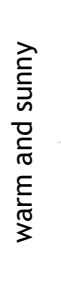 } & \multirow{3}{*}{ 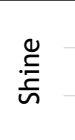 } & Interior_Uninfested (A) - Edge_Uninfested (B) & 1 & 1.02 & 0.316 \\
\hline & & Interior_Uninfested (A) - Edge_Infested (C) & 1 & 49.77 & $<0.001$ \\
\hline & & Edge_Uninfested (B) - Edge_Infested (C) & 1 & 17.91 & $<0.001$ \\
\hline & \multirow{3}{*}{$\begin{array}{l}3 \\
0 \\
0 \\
\tilde{T} \\
\tilde{n}\end{array}$} & Interior_Uninfested (A) - Edge_Uninfested (B) & 1 & 0 & 0.958 \\
\hline & & Interior_Uninfested (A) - Edge_Infested (C) & 1 & 9.1 & 0.003 \\
\hline & & Edge_Uninfested (B) - Edge_Infested (C) & 1 & 3.13 & 0.081 \\
\hline \multirow{6}{*}{ 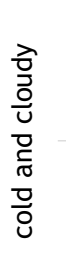 } & \multirow{3}{*}{ 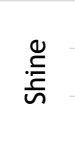 } & Interior_Uninfested (A) - Edge_Uninfested (B) & 1 & 6.83 & 0.011 \\
\hline & & Interior_Uninfested (A) - Edge_Infested (C) & 1 & 12.62 & $<0.001$ \\
\hline & & Edge_Uninfested (B) - Edge_Infested (C) & 1 & 4.69 & 0.033 \\
\hline & \multirow{3}{*}{$\begin{array}{l}z \\
0 \\
\frac{0}{0} \\
\frac{0}{n}\end{array}$} & Interior_Uninfested (A) - Edge_Uninfested (B) & 1 & 0.65 & 0.423 \\
\hline & & Interior_Uninfested (A) - Edge_Infested (C) & 1 & 3.1 & 0.082 \\
\hline & & Edge_Uninfested (B) - Edge_Infested (C) & 1 & 0.44 & 0.506 \\
\hline
\end{tabular}

Tab. 4 - Comparison of mean values ( \pm standard error, SE) of bark temperatures (captured using thermal camera) and phloem temperatures (measured using thermal needles inserted in the phloem) from shine and shadow sides of trees and different measurement days.

\begin{tabular}{|c|c|c|c|c|c|}
\hline Day & Side & Plot & $\begin{array}{c}\text { Bark } \\
\text { temperature } \\
\left({ }^{\circ} \mathrm{C}\right)\end{array}$ & $\begin{array}{c}\text { Phloem } \\
\text { temperature } \\
\left({ }^{\circ} \mathrm{C}\right)\end{array}$ & $\begin{array}{c}\text { Difference } \\
\left({ }^{\circ} \mathrm{C}\right)\end{array}$ \\
\hline \multirow{4}{*}{ 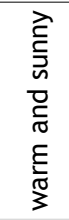 } & \multirow{2}{*}{ 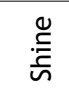 } & Interior_Uninfested (A) & $25.5 \pm 3.77$ & $21.8 \pm 0.89$ & 3.8 \\
\hline & & Edge_Uninfested (B) & $40.5 \pm 2.54$ & $34.4 \pm 1.61$ & 6.1 \\
\hline & \multirow{2}{*}{$\begin{array}{l}3 \\
0 \\
0 \\
\frac{0}{n} \\
\text { n }\end{array}$} & Interior_Uninfested (A) & $25.6 \pm 1.14$ & $21.5 \pm 0.82$ & 4.1 \\
\hline & & Edge_Uninfested (B) & $29.2 \pm 1.48$ & $27.3 \pm 1.02$ & 1.8 \\
\hline \multirow{4}{*}{ 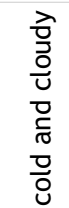 } & \multirow{2}{*}{ 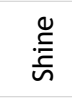 } & Interior_Uninfested (A) & $6.4 \pm 0.96$ & $4.1 \pm 0.44$ & 2.3 \\
\hline & & Edge_Uninfested (B) & $14.8 \pm 2.20$ & $10.0 \pm 1.11$ & 4.8 \\
\hline & \multirow{2}{*}{$\begin{array}{l}3 \\
\frac{3}{0} \\
\frac{\pi}{n} \\
\text { n }\end{array}$} & Interior_Uninfested (A) & $6.3 \pm 1.06$ & $3.9 \pm 0.40$ & 2.4 \\
\hline & & Edge_Uninfested (B) & $8.6 \pm 1.28$ & $6.8 \pm 0.65$ & 1.8 \\
\hline
\end{tabular}

from the fifth measurement. The temperature courses of both sides of uninfested trees in the interior were similar, with the difference not exceeding $1{ }^{\circ} \mathrm{C}$. The results from the cold and cloudy day showed that the infested trees also had significantly higher temperatures on the shine side from the morning hours, when the difference between sides was the highest.

The crown temperature course was similar in all plots on the warm and sunny day (Fig. 5a), with relatively small but significant differences for some measurements. On the cold and cloudy day (Fig. 5b), the crown temperature course followed the same trend in all plots, with the same course of air temperature and relatively small but significant differences for some measurements.

Role of incoming solar radiation on the temperature of healthy and bark-beetle infested trees

On the warm and sunny day (Tab. 3), the differences between bark-beetle infested trees on the forest edge and healthy uninfested trees on the forest edge and in the forest interior from the shine side were highly statistically significant. This indicated that the state of the trees, infested or not, has a greater effect on surface temperature than incoming solar radiation. The only statistically significant difference from the shaded side was found between infested and healthy trees in the forest interior, though the difference between infested and healthy trees on the forest edge was close to statistical significance.

On cold and cloudy days (Tab. 3), the largest significant difference in the shine side was, as expected, between the infested trees on the forest edge and healthy trees in the interior. Differences between other plots were also statistically significant.

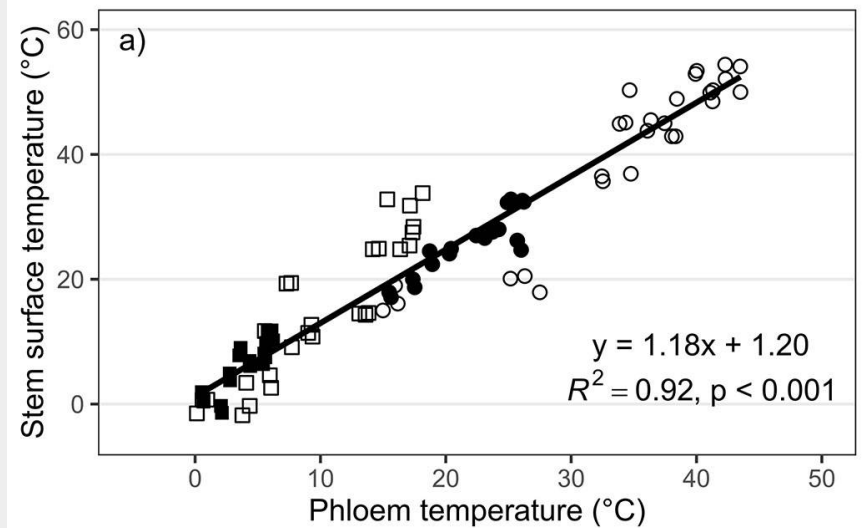

- Edge_Uninfested (B), warm and sunny day

- Interior_Uninfested (A), warm and sunny day

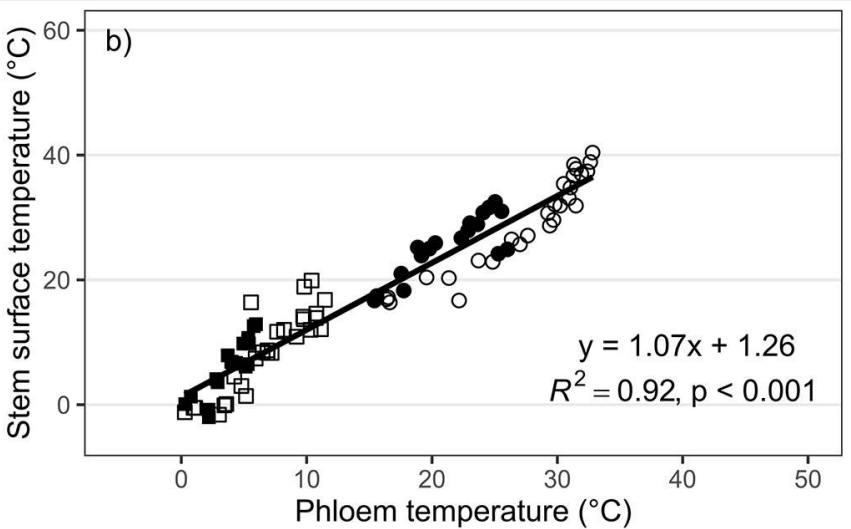

․ Edge Uninfested (B), cold and cloudy day

- Interior_Uninfested (A), cold and cloudy day

Fig. 6 - Correlation between temperatures obtained from thermal camera and thermal needles for (a) shine and (b) shaded side of trees. The belonging of the obtained points in the graph to the individual groups of trees and the day of measurement are graphi cally differentiated as follows: uninfested trees in the forest interior (plot A) on warm and sunny day are represented by black circle; uninfested trees on the forest edge (plot $B$ ) on warm and sunny day are represented by white circle; uninfested trees in the forest interior (plot A) on cold and cloudy day are represented by black square; uninfested trees on the forest edge (plot B) on warm and sunny day are represented by white square. 
Relationship between tree stem surface temperature and phloem temperature

A significant coefficient of determination $\left(R^{2}=0.92\right)$ for the shine side with a mean temperature of $22.9{ }^{\circ} \mathrm{C}$ from the thermal camera and $18.5^{\circ} \mathrm{C}$ from thermal needles was obtained (Fig. 6a). The most sun-exposed were the uninfested trees on the forest edge (plot $B$ ) with the mean surface temperature of $40.5 \pm 2.54{ }^{\circ} \mathrm{C}$ (Tab. 4) and mean phloem temperature of $34.4 \pm 1.61^{\circ} \mathrm{C}$. However, starting with the fourth measurement, the surface temperatures were above $40^{\circ} \mathrm{C}$ with a maximum of $54.4{ }^{\circ} \mathrm{C}$ and a mean of $48.6^{\circ} \mathrm{C}$. In contrast, phloem tem peratures were above $33{ }^{\circ} \mathrm{C}$ with a maximum of $43.5{ }^{\circ} \mathrm{C}$ and a mean of $39{ }^{\circ} \mathrm{C}$. The mean difference between the stem surface and the phloem temperatures during this period was $9.6^{\circ} \mathrm{C}$. For the shadow side, a significant coefficient of determination $\left(R^{2}\right.$ $=0.92$ ) with a mean temperature of $17.72{ }^{\circ} \mathrm{C}$ from the thermal camera and $15.34^{\circ} \mathrm{C}$ from thermal needles was obtained (Fig. 6b).

\section{Discussion}

\section{Vertical temperature distribution}

Our results showed that the temperature on the trunk base is influenced not only by solar radiation, but also by the local microclimate. A strong effect is related to dis tance from the soil surface. The temperature at the trunk base is much higher com pared to other measurement heights. Tem peratures are higher on the sunny part of the trunk. This agrees with our observations of early spring bark beetle attacks on forest edges in NP Šumava (Jakuš R, unpublished observations). In spring swarming, bark beetles first attack trees on forest edges at the base of the trunk (Zumr 1985). Contrary to our findings, Powell (1967) re ported lower temperatures at the base of lodgepole pine trunks than the rest of the bole. Although it is a different species from Norway spruce, both species have similarly finely scaly bark with similar thermal prop erties (Nicolai 1986). So, according to Pow ell (1967), possible contributing factors to the lower temperatures at the base included the lower temperature of xylem water coming from the roots, conduction of heat between the trees and ground, in creased bark thickness nearer to the ground, and lower air temperature near the ground that persisted for most of the $24 \mathrm{~h}$ period within the forest stand. It seems that the base of the trunk is strongly influenced by many factors that affect the microclimate of the tree. Powell (1967) in dicated higher trunk sections as being more similar in temperature. We concluded that the temperature at the trunk base was not appropriate for further analysis.

Crowns tend to maintain stable temperatures, even on infested trees. The measurements of crown temperatures were not suitable for further analysis of these differences because this would involve different types of measurement (i.e., surface and distance). Based on our results, we determined the optimal height of this measurement to be $1.3 \mathrm{~m}$. An important factor is the angle of measurement, which should be perpendicular to the measured surface, as recommended by the manufacturer, to achieve the highest accuracy. However, we recorded almost equal temperatures on the tree trunk $1.3 \mathrm{~m}$ above the ground on the shine side. This indicated that for other thermal camera applications, the whole profile of the tree trunk can be used. For example, scanning forest edges from greater distances would be possible, focusing on the part of the tree between the trunk base and the crown deployment height.

On the shaded side, the soil surface has a stronger influence, heating the tree stems. The temperature is highest at the base and gradually decreases upward along the stem. On the shine side, the temperature is more directly determined by direct solar radiation.

\section{Differences between trees in forest stand interior and at newly created forest edge}

Healthy or infested trees on forest edges had higher temperatures than trees in the stand interior. This corresponds with the preference of I. typographus to attack trees on forest edges (Jakuš et al. 2011, Kautz et al. 2013). A higher level of solar radiation generally increases surface temperature. Due to the effect of transpiration, the surface temperature of relatively healthy trees on the forest edge did not increase directly with exposed irradiation, as observed for the infested ones. Our results correspond with those of Hietz et al. (2005), especially with the described cooling effect of transpiration on sapwood and cambium temperature.

With lower irradiation, healthy trees on the forest edge maintained their surface temperatures near those of trees in the interior. In the case of interior trees, we found a similar temperature pattern for shine and shaded parts of the trunk. This is caused by low irradiation in the stand interior and the forest stand microclimate.

\section{Differences between healthy and bark- beetle infested trees}

Bark-beetle infested trees on the forest edge had higher trunk temperatures than healthy trees on the forest edge and in the interior, whereas both groups of trees on the forest edge were exposed to similar amounts of incoming solar radiation. This agrees with the results of Powell (1967) on lodgepole pines infested by Dendroctonus ponderosae. According to that study, freshly infested trees had subcortical temperatures similar to those of uninfested ones. However, as the beetle broods developed, the water content of the sapwood lowered, and the brood experienced higher subcortical temperatures and greater extremes of temperature. On uninfested trees on the forest edge (plot $B$ ) and in the forest interior (plot $A$ ), we report a strong correlation between phloem and bark surface temperatures. This agrees with the results reported by Powell (1967) and Hietz et al. (2005), and also demonstrates the precision of thermal camera measurement, which has potential for tree physiology and bark beetle development modelling. The most extreme values of surface bark temperatures on uninfested trees were recorded on the forest edge (plot B) from the shine side during the warm and sunny day, especially during noon and afternoon. During this period a maximum of $54.4{ }^{\circ} \mathrm{C}$ was recorded on the bark surface, but the temperatures recorded in the phloem were on average $9.6{ }^{\circ} \mathrm{C}$ lower. This agrees with the study of Nicolai (1986), who described the insulating properties of bark in different tree species and types of bark. According to Annila (1969), not only temperature but also relative humidity affects the survival of adults and offspring of Ips typographus. The relative humidity is naturally higher in the galleries under the bark and thus reduces the risk of mortality from drying out. Larvae, as well as pupae and adults, survived at $45^{\circ}$ and $46{ }^{\circ} \mathrm{C}$ for 6 hours, at $47^{\circ} \mathrm{C}$ for 4 hours and at $48^{\circ} \mathrm{C}$ for 2 hours. Only temperatures exceeding $47^{\circ} \mathrm{C}$ appear to be fatal in the wild, but such temperatures only stay for a few hours and the bark beetles survive this without loss. Karasev et al. (2017) used semiconductor thermoresistors to detect trends in stem temperatures of Scots pine in different groups based on the physiological state of trees. The temperature was found to have a strong inverse correlation with the state of the trees, confirming that the method of assessing physiological state using temperature parameters allows early diagnosis of decreased viability of conifers.

\section{Canopy layer}

Only a few studies have focused on bark beetle detection using UAVs (Senf et al. 2017, Hall et al. 2016). For example, Näsi et al. (2015) and Näsi et al. (2018) distinguished between healthy and infested and dead trees with overall accuracies of $76 \%$ and $81 \%$, respectively, using hyperspectral UAV-borne images in Finland; however, they did not distinguish between healthy trees and those in an early stage of infestation.

Using a handheld thermal camera, we measured the bottom, and shady part of the crown, and our study is thus limited. Measuring crown temperature from the bottom is not the most appropriate method. We cannot be sure of the temperatures on the sunny/upper part of the canopy because significant temperature differences could exist between the upper and lower parts of the crown (Reinert et al. 2012).

We can assume that the healthy canopy layer of uninfested trees tends to cool by transpiration and maintains stable and ho- 
mogeneous temperatures (Helliker \& Richter 2008). Air flow could also be an important factor regulating the temperature of the crown layer. Even the canopies of barkbeetle infested trees had temperatures similar to healthy trees. This may be due to bark beetles attacking phloem (Wermelinger 2004). Sap flow and cooling by transpiration can be affected only later by fungal infection initiated by bark beetles (Paine et al. 1997, Wullschleger et al. 2004, Hubbard et al. 2013). Conversely, Junttila et al. (2017) reported higher temperatures in severely defoliated canopies, using an airborne thermal imaging system. Golomb et al. (2015) found that red palm weevil infestation caused water stress in palm leaves and increased canopy temperature.

\section{Conclusions}

We conclude handheld thermal cameras show potential for identification of barkbeetle attacked trees. Bark-beetle infested trees show higher daytime trunk temperatures than healthy uninfested trees in the stand interior and trees on the forest edge. The difference is more noticeable on warm and sunny days. We showed that bark beetle infestation can be detected earlier using tree trunk temperatures rather than crown temperatures. However, this issue needs further investigation with the use of UAVor aircraft-based thermal cameras.

Our findings demonstrate the potential for identification of bark-beetle infested trees with a handheld thermal camera by scanning tree trunks on bright sunny days, particularly on forest edges. Investigations should be performed during periods when the forest edge is exposed to direct solar radiation. However, identification of barkbeetle attacked trees by trained foresters is highly subjective and time-consuming in the case of an attack on higher parts of a tree trunk. Identification of fresh attacks requires physically checking every tree. Remote identification of bark-beetle attacked trees using thermal cameras could increase the efficacy and speed of the process. The method could be more efficient in spring or under mountain conditions when initial attacks start on the forest edge. Later, when attacks spread to the forest interior, the use of a handheld thermal camera may be limited. An efficient protocol for this requires further development.

\section{Author contribution}

A.M., field work, data measurement and analyses, writing the paper; R.J., experimental design, field work, result evaluation, writing the paper; M.B., experimental design, data measurement and analyses, results evaluation, writing the paper.

\section{Funding}

This work was supported as a part of the following projects: (1) Slovak Research and Development Agency, Contract nos. APVV19-0606 and APVV-15-0761; (2) Research Agency, no. ITMS 26220220109 "Prognos- tic-information systems for improving the efficiency of management", supported by the Research \& Development Operational Programme funded by the ERDF; (3) Grant Agency of the Ministry of Education and the Slovak Academy of Sciences (VEGA 2/0176/17); (4) EXTEMIT-K grant no. Z.02.1. 01/0.0/0.0/15_003/0000433, financed by Operational Programme Research, Development and Education (OPRDE).

\section{References}

Abdullah H, Darvishzadeh R, Skidmore AK, Groen TA, Heurich M (2018). European spruce bark beetle (Ips typographus L.) green attack affects foliar reflectance and biochemical properties. International Journal of Applied Earth Observation and Geoinformation 64: 199-209. doi: 10.1016/j.jag.2017.09.009

Annila E (1969). Influence of temperature upon the development and voltinism of Ips typographus L. (Coleoptera, Scolytidae). Annales Zoologici Fennici 6: 161-208.

Baier P, Bader R (1997). Gehalt und Emission von Monoterpenen der Fichtenrinde und deren Bedeutung für die Primärattraktion von Borkenkäfern (Coleoptera, Scolytidae). [Monoterpene content and monoterpene emission of Norway spruce bark and their relation to the primary attraction of bark beetles (Coleoptera, Scolytidae)]. Mitteilungen Der Deutschen Gesellschaft für Allgemeine fnd Angewandte Entomologie 11: 639-643. [in German]

Buitrago MF, Groen TA, Hecker CA, Skidmore AK (2016). Changes in thermal infrared spectra of plants caused by temperature and water stress. ISPRS Journal of Photogrammetry and Remote Sensing 111: 22-31. - doi: 10.1016/j.isprsj prs.2015.11.003

Costa JM, Grant OM, Chaves MM (2013). Thermography to explore plant-environment interactions. Journal of Experimental Botany 64: 3937-3949. - doi: 10.1093/jxb/erto29

Golomb O, Alchanatis V, Cohen $\mathrm{Y}$, Levin N, Cohen $Y$, Soroker $V$ (2015). Detection of red palm weevil infected trees using thermal imaging. In: Proceedings of the " $10^{\text {th }}$ European Conference on Precision Agriculture, ECPA 2015". Wageningen Academic Publishers, Wageningen, Netherlands, pp. 643-650. - doi: 10.3920/978-90-8686814-8_80

Hall RJ, Castilla G, White JC, Cooke BJ, Skakun RS (2016). Remote sensing of forest pest damage: A review and lessons learned from a Canadian perspective. Canadian Entomologist 148: 296356. - doi: 10.4039/tce.2016.11

Helliker BR, Richter SL (2008). Subtropical to boreal convergence of tree-leaf temperatures. Nature 454: 511-514. - doi: 10.1038/nature07031 Hietz P, Baier P, Offenthaler I, Führer E, Rosner $\mathrm{S}$, Richter $\mathrm{H}$ (2005). Tree temperatures, volatile organic emissions, and primary attraction of bark beetles. Phyton - Annales Rei Botanicae 45: 341-354. [online] URL: http://www.research gate.net/publication/263358481

Hubbard RM, Rhoades CC, Elder K, Negron J (2013). Changes in transpiration and foliage growth in lodgepole pine trees following mountain pine beetle attack and mechanical girdling. Forest Ecology and Management 289: 312-317. - doi: 10.1016/j.foreco.2012.09.028
IUSS Working Group WRB (2014). World reference base for soil resources 2014. World Soil Resources Reports no. 106, FAO, Rome, Italy, pp. 192.

Jakuš R, Edwards-Jonášová $\mathrm{M}$, Cudlín $\mathrm{P}$, Blaenec M, Jeík M, Havlíček F, Moravec I (2011). Characteristics of Norway spruce trees (Picea abies) surviving a spruce bark beetle (Ips typographus L.) outbreak. Trees - Structure and Function 25: 965-973. - doi: 10.1007/s00468-011-0571-9 Jones HG (2004). Application of thermal imaging and infrared sensing in plant physiology and ecophysiology. Advances in Botanical Research 41: 107-163. - doi: 10.1016/s0065-2296(04)410039

Junttila $S$, Vastaranta $M$, Hämäläinen J, LatvaKäyrä P, Holopainen M, Hernández Clemente R, Hyyppä H, Navarro-Cerrillo RM (2017). Effect of forest structure and health on the relative surface temperature captured by airborne thermal imagery - Case study in Norway Spruce-dominated stands in Southern Finland. Scandinavian Journal of Forest Research 32: 154-165. - doi: 10.1080/02827581.2016.1207800

Karasev VN, Karaseva MA, Romanov EM, Mukhortov DI (2017). Rapid thermal method for early diagnosis of the physiological state of Scots pine trees. Russian Journal of Ecology 48: 109-115. - doi: 10.1134/S1067413617020072

Kautz M, Schopf R, Ohser J (2013). The "sun-effect": microclimatic alterations predispose forest edges to bark beetle infestations. European Journal of Forest Research 132: 453-465. - doi: 10.1007/s10342-013-0685-2

Kirisits T, Offenthaler I (2002). Xylem sap flow of Norway spruce after inoculation with the bluestain fungus Ceratocystis polonica. Plant Pathology 51: 359-364. - doi: 10.1046/j.1365-3059.2002. 00722.x

Lapin M, Faško P, Melo M, Stastny P, Tomlain J (2002). Climatic regions 1:1.000.000. In: "Landscape Atlas of the Slovak Republic" (Hrnčiarová $\mathrm{T}$ ed). Ministry of Environment of the Slovak Republic, Bratislava, and Slovak Environment Agency, Banská Bystrica, Slovak Republic, pp. 344.

Latifi H, Fassnacht FE, Schumann B, Dech S (2014). Object-based extraction of bark beetle (Ips typographus L.) infestations using multidate LANDSAT and SPOT satellite imagery. Progress in Physical Geography 38: 755-785. doi: 10.1177/0309133314550670

Lausch A, Erasmi S, King DJ, Magdon P, Heurich $M$ (2016). Understanding forest health with remote sensing. Part I - A review of spectral traits, processes and remote-sensing characteristics. Remote Sensing 8: 1029. - doi: 10.3390/ rs8121029

Lausch A, Erasmi S, King DJ, Magdon P, Heurich $M$ (2017). Understanding forest health with remote sensing. Part II - A review of approaches and data models. Remote Sensing 9: 129. - doi: $10.3390 /$ rs9020129

Leuzinger S, Körner C (2007). Tree species diversity affects canopy leaf temperatures in a mature temperate forest. Agricultural and Forest Meteorology 146: 29-37. - doi: 10.1016/j.agrfor met.2007.05.007

Marešová J, Majdák A, Jakuš R, Hradecky J, Kalinová B, Blazenec M (2020). The short-term effect of sudden gap creation on tree tempera- 
ture and volatile composition profiles in a Norway spruce stand. Trees - Structure and Function 34: 1397-1409. - doi: 10.1007/s00468-02002010-w

Mezei $P$, Jakuš R, Pennerstorfer J, Havašová $M$, Skvarenina J, Ferenčík J, Slivinsky J, Bičárová S, Bilčík D, Blazenec M, Netherer S (2017). Storms, temperature maxima and the Eurasian spruce bark beetle Ips typographus. An infernal trio in Norway spruce forests of the Central European High Tatra Mountains. Agricultural and Forest Meteorology 242: 85-95. - doi: 10.1016/j.agrfor met.2017.04.004

Näsi R, Honkavaara E, Blomqvist M, LyytikäinenSaarenmaa P, Hakala T, Viljanen N, Kantola T, Holopainen $M$ (2018). Remote sensing of bark beetle damage in urban forests at individua tree level using a novel hyperspectral camera from UAV and aircraft. Urban Forestry and Ur ban Greening 30: 72-83. - doi: 10.1016/j.ufug.20 18.01.010

Näsi R, Honkavaara E, Lyytikäinen-Saarenmaa P, Blomqvist $\mathrm{M}$, Litkey $\mathrm{P}$, Hakala $\mathrm{T}$, Viljanen $\mathrm{N}$, Kantola T, Tanhuanpää T, Holopainen M (2015). Using UAV-based photogrammetry and hyperspectral imaging for mapping bark beetle damage at tree-level. Remote Sensing 7: 1546715493. - doi: 10.3390/rs71115467

Nicolai V (1986). The bark of trees: thermal prop- erties, microclimate and fauna. Oecologia 69: 148-160. - doi: 10.1007/BF00399052

Paine TD, Raffa KF, Harrington TC (1997). Interactions among scolytid bark beetles, their associated fungi, and live host conifers. Annual Review of Entomology 42: 179-206. - doi: 10.1146/ annurev.ento.42.1.179

Powell JM (1967). A study of habitat temperatures of the bark beetle Dendroctonus ponderosae Hopkins in lodgepole pine. Agricultural Meteorology 4: 189-201. - doi: 10.1016/00021571(67)90003-9

Reinert S, Bögelein R, Thomas FM (2012). Use of thermal imaging to determine leaf conductance along a canopy gradient in European beech (Fagus sylvatica). Tree Physiology 32: 294-302. - doi: 10.1093/treephys/tps017

Senf C, Seidl R, Hostert P (2017). Remote sensing of forest insect disturbances: current state and future directions. International Journal of Applied Earth Observation and Geoinformation 60: 49-60. - doi: 10.1016/j.jag.2017.04.004

Scherrer D, Bader MKF, Körner C (2011). Drought-sensitivity ranking of deciduous tree species based on thermal imaging of forest canopies. Agricultural and Forest Meteorology 151: 1632-1640. - doi: 10.1016/j.agrformet.2011. 06.019

Smigaj M, Gaulton R, Barr SL, Suárez JC (2015).
UAV-Borne thermal imaging for forest health monitoring: Detection of disease-induced canopy temperature increase. International Archives of the Photogrammetry, Remote Sensing and Spatial Information Sciences - ISPRS Archives 40: 349-354. - doi: 10.5194/isprsarchivesXL-3-W3-349-2015

Stadt KJ, Lieffers VJ (2000). MIXLIGHT: A flexible light transmission model for mixed-species forest stands. Agricultural and Forest Meteorology 102: 235-252. - doi: 10.1016/S01681923(00)00128-3

Wermelinger B (2004). Ecology and management of the spruce bark beetle Ips typographus - A review of recent research. Forest Ecology and Management 202: 67-82. - doi: 10.1016/j.foreco.2004.07.018

Wullschleger SD, McLaughlin SB, Ayres MP (2004). High-resolution analysis of stem increment and sap flow for loblolly pine trees attacked by southern pine beetle. Canadian Journal of Forest Research 34: 2387-2393. - doi: 10.1139/X04-118

Zumr V (1985). Biologie a ekologie lýkožrouta smrkového (Ips typographus) a ochrana proti nemu [Biology and ecology of the spruce bark beetle (Ips typographus) and its control]. ACADEMIA, nakladatelství CSAV, Praha, Czech Republic, pp. 124. 